\title{
MOTIVATIONAL INPUTS RECEIVED BY MIGRATED AND NON-MIGRATED STUDENTS DURING CLASSROOM TEACHING IN JNVS
}

\begin{abstract}
Sujeet Kumar
Dr. Sujeet Kumar- Associate Professor, Department of Education, Guru Ghasidas Vishwavidyalaya (A Central University) Koni, Bilaspur, C.G. 495009

Sumit Kumar Shukla

Sumit Kumar Shukla- P.G. Scholar, Department of Education, Guru Ghasidas Vishwavidyalaya (A Central University) Koni, Bilaspur, C.G. 495009
\end{abstract}

\begin{abstract}
Objective of the present study is to observe the level of motivational inputs received by migrated and non-migrated students of JNVs during classroom teaching. In this research JNV Bilaspur was selected for data collection. Ten migrated students and ten non-migrated students were selected as sample. The self-developed Classroom Motivational Input Scale for Students was used to measure the level of motivational inputs received by students in classroom teaching. The raw score obtained on Classroom Motivational Input Scale for Students were converted to Z-Score for analysis. The results found that there is variation in the motivational inputs received by students during classroom teaching
\end{abstract}

Keywords: Motivational inputs, Migrated and Non-Migrated Students, Classroom Teaching, Z-Score

\section{Introduction}

Swami ji defines education as 'the manifestation of the perfection already in man.' The aim of education is to manifest in our lives the perfection, which is the very nature of our inner self. This perfection is the realization of the infinite power which resides in everything and every-where existence, consciousness and bliss (satchidananda) (Retrieved on $1^{\text {st }}$ of October 2012 from http://www.esamskriti.com/essay-chapters/Education-inthe-Vision-of-Swami-Vivekananda-1.aspx). Dictionary of Education (ed. Good) defines "Education as the aggregate of all the process by which a person develops ability, attitude and other of behaviors of practical value in 
the society in which people are subjected to the influences of a selected and controlled environment (especially that of school) so that they may obtain social competence and optimum individual developments". (Seshadri, C. (1983). Teacher and the Education . New Delhi: NCERT. Page No.84) . This education is provided to the student through Formal learning, Informal learning and non-formal learning. (Source: A Memorandum on Lifelong Learning, European Commission, Unit E-3, http://www.irlgov.ie/educ/ new/LifeLongLearninghtm.htm). The National System of Education envisages a common educational structure. The 10+2+3 structure has now been accepted in all parts of the country. Regarding the further break-up of the first 10 years efforts will be made to move towards an elementary system comprising 5 years of primary education and 3 years of upper primary, followed by 2 years of High School. Efforts will also be made to have the +2 stage accepted as a part of school education throughout the country (National Policy on Education, 1986(Modified in 1992, pp.5). Broadly we can divide formal education in to primary, secondary and higher education. Secondary education is given through government school, Aided school, unaided school, Private school,Public school, Kendriya Vidyalaya, and Jawahar Navodaya Vidyalaya. The National Policy on education, 1986, envisaged the establishment of Navodaya Vidyalayas in each district of the country. The Vidyalayas are fully residential coeducational institutions providing education from classes $6^{\text {th }}$ to $8^{\text {th }}$. Initially two experimental schools were established in 1985-86. These Vidyalayas aim at identification and development of talented, bright and gifted children predominantly from rural areas who may otherwise find it difficult to avail of good educational opportunities. The Jawahar Navodaya Vidyalayas are working on following objectives:

To provide good quality education including a strong component of India's cultural heritage, inculcation of values, awareness of environment, adventure activities and physical education to talented children belonging predominantly to rural areas, without regard to their family socio-economic condition.

To ensure that all students of JNV attain a reasonable level of competence in three language as envisaged in three language formula, and

To serve, in each district, as a focal point for improvement in the quality of school education in general, through sharing of experience and facilities. (K.S., Saran (2004). "Navodaya Vidyalaya”. Encyclopedia of Indian Education. (Vol. II Page No. 1240).New Delhi : NCERT)

Navodaya Vidyalayas aim at inculcating values of national integration through migration scheme through which the inter-regional exchange of students between Hindi and Non-Hindi speaking States and vice-versa takes place for one academic year. Efforts are made to promote 
better understanding of the unity in diversity and cultural heritage through various activities. The Regional Language is generally the medium of instruction from Class-VI to VIII and from Class- IX onwards, it is English for Science and Mathematics and Hindi for Humanities subjects. Under the three language formula, the students learn regional language, English and regional language of migrated state. (Retrieved on $1^{\text {st }}$ of October 2012 from http://www.navodaya.nic.in/welcome\%20sbs.htm)Teacher teaches their student in class through various methods and during their teaching they give verbal and non-verbal motivation to their students. These motivational inputs given by teacher motivate the student and they concentrate on their study. These motivated studies also affect the student's achievement. Migration scheme in JNVs were introduced to foster national integration and to minimize the cultural gap. In this scheme the inter regional exchange of students between Hindi and Non-Hindi speaking States and vice-versa takes place for one academic year. Efforts are made to promote better understanding of the unity in diversity and cultural heritage through various activities (Retrieved on $1^{\text {st }}$ of October 2012 from http://www. navodaya.nic.in/welcome\%20sbs.htm). When student migrate from their Non-Hindi speaking States JNV to Hindi speaking States JNV, they met with new culture, food habits, environment and the most important the language. Language is the most important factor which connects the students directly to the teacher, students and local people of the JNV where they migrated. During academic activities, playground activities and in hostel they communicate with each other in local regional language. The students of non-Hindi background are not comfort freely in the local language. Although the medium of study in class ix is in English but teacher often communicate with their students in regional language. During teaching the teacher motivates their students for study and to get their answers. All teachers are expected to motivate students during teaching in classroom. So migrated and non-migrated students of class during classroom teaching receive equal motivational input or not. There is any effect in receiving motivation due to different language and culture.

a) Is migrated and non-migrated students receiving equal motivational input during classroom teaching?

Researcher like Freeman, John and Klinger (2012) Heyman, GailD. And Dweck, Carol (2012Yoshino, Asako (2012) De Freitas (2012) Kim, Kyung (2011) Rodgers and Summers (2008) Lens (2002) and Shim and Ryan (2002) in his study find that teachers provide motivational inputs at different level but they never demotivate their students and their motivational inputs affects students achievement, sometime students also perform through intrinsic motivation. So objective of the study is: 
To study the level of motivational inputs received by migrated and non-migrated students of JNV during classroom teaching.

\section{Research Hypothesis:}

After formulating the objective of study, researcher needs to formulate the hypothesis for the process of research. Basically scientific research which keeps scientific approach based on the hypothesis. These hypotheses are formulated on the basis of previous research reviews. Here researcher formulated following research hypothesis:

There is difference in the level of motivational inputs received by migrated and non-migrated students of JNV during classroom teaching.

Method: For the testing of hypothesis data has been collected through normative survey method which was followed by the researcher. The data analysis and their presentation are based on Z-Score value.

\section{Sample and sampling:}

Purposive stratified sample has been selected in three levels. In first level JNV Bilaspur has been selected as a purposive sample in first phase which is shown in table no. 1

Table No. 1

\begin{tabular}{|c|c|}
\hline No. of JNVs in Chhattisgarh & Purposive selected JNVs \\
\hline 16 & 1 \\
\hline
\end{tabular}

In second phase researcher has classified the group of migrated and non-migrated students of class ix has been selected which is shown in table no. 2

Table No. 2

\begin{tabular}{|c|c|}
\hline \multirow{2}{*}{ JNV Bilaspur } & Migrated student \\
\cline { 2 - 2 } & Non-migrated student \\
\hline
\end{tabular}

After dividing in to two group researcher has taken third level random sampling which has 10 migrated and 10 non migrated students which is shown in table no. 3

Table No. 3

\begin{tabular}{|c|c|}
\hline No. of migrated students & No. of non-migrated students \\
\hline 10 & 10 \\
\hline
\end{tabular}

Tool: Researcher developed Classroom Motivational Input Scale for Students (CMISS) for the collection of data. This tool has been administrated on students for measuring the level of motivational inputs received by migrated and non-migrated students during classroom teaching.

Analysis Procedure: The raw score obtained on Classroom Motivational Input Scale for Students were converted to Z-Score for their analysis. Division of migrated and non-migrated students according to level 
of motivation inputs received in the Classroom Motivational Input Scale for Students is given in table no. 4

Table No. 4

\begin{tabular}{|c|c|c|c|c|}
\hline S.N. & Range Of Z- Scores & Level of Motivation & $\begin{array}{c}\text { No. of Migrated } \\
\text { Students }\end{array}$ & $\begin{array}{c}\text { No. of Non- } \\
\text { Migrated Students }\end{array}$ \\
\hline 1 & $1.43 \sigma$ to $0.81 \sigma$ & Extreme & 2 & 2 \\
\hline 2 & $0.81 \sigma$ to $0.18 \sigma$ & High & 4 & 2 \\
\hline 3 & $0.18 \sigma$ to $-0.44 \sigma$ & Average & 2 & 1 \\
\hline 4 & $-0.44 \sigma$ to $-1.07 \sigma$ & Below Average & 1 & 2 \\
\hline 5 & $-1.07 \sigma$ to $-1.69 \sigma$ & Lowest & 1 & 3 \\
\hline Total & $1.43 \sigma$ to $-1.69 \sigma$ & & 10 & 10 \\
\hline
\end{tabular}

Results

The raw scores of students were converted in to Z-Score. Out of ten migrated students 2 students were reported for receiving extreme motivation, 4 migrated students for high motivation, 2 migrated students for average motivation, 1 migrated student for below average motivation and 1 students for receiving lowest motivation among all 10 migrated students. Out of ten non-migrated students 2 non-migrated students were reported for receiving extreme motivation, 2 non-migrated students for high motivation, 1 nonmigrated student for average motivation, 2 non- migrated students for below average motivation and 3 non-migrated students for receiving lowest motivation among all 10 non-migrated students.

\section{Discussion}

The hypotheses formulated on objective were analyzed with Z-Score of migrated and non-migrated students obtained in Classroom Motivational Input Scale for Students and it was found that all migrated and non-migrated students were not receiving equal motivational input in the class. Out of ten migrated students 2 students reported for receiving extreme motivation, 4 migrated students for high motivation, 2 migrated students for average motivation, 1 migrated students for below average motivation and 1 students for receiving lowest motivation among all 10 migrated students. Out of ten non-migrated students 2 students reported for receiving extreme motivation, 2 non-migrated students for high motivation, 1 non-migrated students for average motivation, 2 non- migrated students for below average motivation and 3 non-migrated students for receiving lowest motivation among all 10 non-migrated students.

\section{Conclusion}

On the basis of above findings it can be concluded that although it seems that all students receives equal motivational input during classroom teaching but in this research it was found that there was variation in 
motivational inputs received by migrated and non-migrated students. During classroom teaching migrated and non-migrated students were reported for receiving extreme motivational input to lowest motivational input.

\section{References:}

Retrieved on $1^{\text {st }}$ of October 2012 from http://www.esamskriti.com/essaychapters/Education-in-the-Vision-of-Swami-

Vivekananda1.aspx3, http://www.irlgov.ie/e

duc/new/LifeLongLearninghtm.htm

Seshadri, C. (1983). Teacher and the Education. New Delhi: NCERT. Page No.84

National Policy on Education, 1986(Modified in 1992, pp.5

K.S., Saran (2004). "Navodaya Vidyalaya”. Encyclopedia of Indian Education. Vol. II Page No. 1240.New Delhi, NCERT

Retrieved on $1^{\text {st }}$ of October 2012 from http://www.navodaya.nic. in/welcome\%20sbs.htm

Freeman, John and Klinger, Do Retrieved on $1^{\text {st }}$ of October 2012 from http://link.springer.com/article/10.1007\%2Fs11218-011-9155-1

Heyman, GailD. And Dweck, Carol S Retrieved on $1^{\text {st }}$ of October 2012 from http://link.springer.com/article/10.1007\%2FBF00991653

Yoshino, Asako International Review of Education, April 2012, Volume 58, Issue 2, pp. 199-219, Retrieved on $1^{\text {st }}$ of October 2012 from http://link.springer.com/article/10.1007\%2Fs10212-012-0132-7

DeFreitas. Social Psychology of Education March 2012, Volume 15, Issue 1, pp. 109-123, Retrieved on $1^{\text {st }}$ of October 2012 from http://link.springer.com/article/10.1007\%2Fs11218-011-9172-0

Kim, Kyung, September 2011, Volume 24, Issue 8, pp. 861-881,Retrieved on $1^{\text {st }}$ of October 2012 from http://link.springer.com/article/ 10.1007\%2Fs11145-010-9229-zReading

Rodgers and Summers Review, June 2008, Volume 20, Issue 2, pp. 171190,Retrieved on $1^{\text {st }}$ of October 2012 from http://link.springer.com /article/10.1007\%2Fs10648-008-9072-9)

Lens, Willy. Trends and Prospects in Motivation Research 2002, pp. 2336,Retrieved on $1^{\text {st }}$ of October 2012 from http://link.springer.com /chapter/10.1007\%2F0-306-47676-2_2

Shim and Ryan. Trends and Prospects in Motivation Research 2002, pp. 2336, Retrieved on $1^{\text {st }}$ of October 2012 from http:/link.springer.com/ article/10.1007\%2Fs10212-012-0132-7 